\section{ARS Tech}

Authors retain copyright

\section{Applied Research and Smart Technology}

Journal homepage: www.journals2.ums.ac.id/index.php/arstech

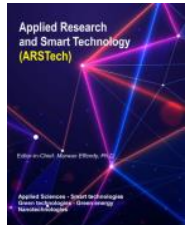

ISSN 2722-9645

\title{
Characteristics of hardness and microstructure of extraction forceps for dental and oral care made of stainless-steel
}

\author{
Nur Kholis ${ }^{1 *}$, Nuryanto Nuryanto ${ }^{2}$, Arif Mustofa ${ }^{3}$ \\ ${ }^{* 1,2}$ Department of Mechanical Engineering, Faculty of Engineering, Universitas Wahid Hasyim, Semarang. 50236. Indonesia. \\ ${ }^{3}$ Politeknik Maritim Negeri Indonesia. Semarang. 50233. Indonesia.
}

${ }^{*}$ Corresponding author: nurkholis@unwahas.ac.id

Permalink (DOI): https://doi.org/10.23917/arstech.v1i2.184

\begin{tabular}{|c|c|}
\hline ARTICLE INFO & ABSTRACT \\
\hline Article history: & The reliability of medical devices such as extraction forceps is vital for dental and \\
\hline & oral care. Apart from having hygienic properties, the extraction forceps must be \\
\hline Received 20 Sep 2020 & strong and resistant to corrosion. This study evaluates the effects of tempering \\
\hline Revised 10 Oct 2020 & temperature on the hardness and microstructure of a medical device's material \\
\hline Accepted 23 Nov 2020 & made from stainless-steel DIN 4021. In the experiments, a heat treatment \\
\hline Available online 29 Nov 2020 & process was carried out previously with a temperature of $1,050^{\circ} \mathrm{C}$ and a holding \\
\hline Published regularly 01 Dec 2020 & $\begin{array}{l}\text { time of } 20 \text { minutes. A quenching process was conducted using a cooling channel } \\
\text { that flowed with water at } 10-20^{\circ} \mathrm{C} \text {. After the heat treatment, the material was }\end{array}$ \\
\hline Keywords: & subjected to a tempering process with temperature variations of 200,400 , and \\
\hline Hardness & $600^{\circ} \mathrm{C}$. The research results indicated that the heat treatment process could \\
\hline ical material & increase the material's hardness - the hardness of the raw material changed from \\
\hline Microstructure & 20 to $48.67 \mathrm{HRC}$ with the heat treatment. The tempering parameters resulted \\
\hline Stainlecc-steel & in the highest hardness of $46.67 \mathrm{HRC}$ at $200^{\circ} \mathrm{C}$ and the lowest value of 42.33 \\
\hline $\begin{array}{l}\text { Stanless-steel } \\
\text { Scanning electron microscopy (SEM) }\end{array}$ & HRC at $600^{\circ} \mathrm{C}$. Microstructure testing using optical microscopy showed that it \\
\hline Scanming electron mincroscopy (JEIV) & $\begin{array}{l}\text { produced ferrite, pearlite, and martensite structures. In contrast, the result of a } \\
\text { microstructure testing using Scanning Electron Microscopy on the surface of the } \\
\text { material is that the higher the tempering temperature, the greater the } \\
\text { microstructures' dimension. }\end{array}$ \\
\hline
\end{tabular}

\section{INTRODUCTION}

Stainless steel or corrosion-resistant steel is known as magic metal has been widely used for human life. This material has reliable mechanical properties and good corrosion resistance [1]. Its applications range from everyday household goods to applications in boilers, automotive, biomedical, and chemical industries [2- $-\underline{4}$. In an earlier time, stainless-steel has been applied to produce the best and most durable products. However, the materials or products made of stainless-steel could only be purchased or accessed by the upper class. As time goes by, 
the application and production of products with stainlesssteel has increased rapidly and become more common and accessible. As a result, the rapid development of technology has significantly impacted the industry, particularly medical devices, for oral and dental care. Most of these tools take advantage of stainless-steel as the raw material due to its corrosion resistance [5][6].

It is necessary to give a heat treatment of material, such as tempering appropriately in the production process. Heat treatment is commonly applied to the raw material to alter its softness property and increase its hardness as needed [Z]. Heat treatment is a combination of heating and cooling a solid material for a certain period to obtain certain properties []]. As recommended by the ISO 13485 standard, medical devices' permissible hardness is $43 \pm 3$ HRC [2].

As commonly known, the negative impact of heat treatment is that the material examined hardness is above the desired standard and becomes brittle. However, tempering can overcome the effects after completing the heat-treatment process. The tempering process may reduce the hardness and the brittle property of a material [10]. The tempering is carried out by reheating a hardened material at a temperature below the critical point to obtain certain ductility and then quenching it. In principle, the process is intended to reduce the brittleness and hardness to meet its use requirements. In addition, tempering serves to increase its toughness and ductility without drastically reducing its hardness [11].

Besides the hardness, the quench hardening process also affects a material's microstructure [12]. The hardening process above the austenite temperature and the quenching process carried out on the raw material produce a martensite phase. The property of martensite microstructures tends to be hard and brittle because of their high hardness [13]. The increased austenitising temperature raises the amount of residual austenite content [10]. The retained austenite subsequently erodes Chromium (Cr) and improve the antirust film. The corrosion resistance of martensitic stainless-steel to the carbide volume fraction is closely related to the carbide precipitation during tempering [14].

The heat treatment process involving hardening, quenching, and tempering turns the microstructures of the steel's initial carbon into martensite, pearlite, or bainite microstructures. This transformation of microstructure also alters its physical and mechanical properties. Therefore, a more in-depth study regarding this kind of change is needed, especially a stainless-steel material for medical devices [15].

Several kinds of research on the material properties of stainless-steel DIN 4021 have been conducted to analyse the effect of a holding time in the material properties' tempering process. A holding time significantly impacts the material properties in terms of hardness and microstructure form [3] [16] .

This research examined the relationship between the tempering temperature and the material's hardness concerning the problem discussed above. The study analyses the relationships between the tempering temperature and the microstructural change using optical microscopy (OM) and scanning electron microscopy (SEM). This study considered some treatment of holding time carried out by Jiang et al. [17].

\section{RESEARCH METHODOLOGY}

This research was realised experimentally in the Material Laboratory of the Faculty of Engineering, Universitas Wahid Hasyim Semarang Indonesia. Figure 1 shows a product of extraction forceps and the samples of the cut specimen. This product is a medical device for oral and dental care, considering that stainless-steel has a relatively high corrosion resistance [18]. The material of stainless-steel DIN 4021 contains $\mathrm{C}=0.16-0.25 \%, \mathrm{Si} \leq 1$, $\mathrm{Mn} \leq 1.5, \mathrm{Cr}=12-14, \mathrm{Mo}=0$, and $\mathrm{Ni}=0.25$.

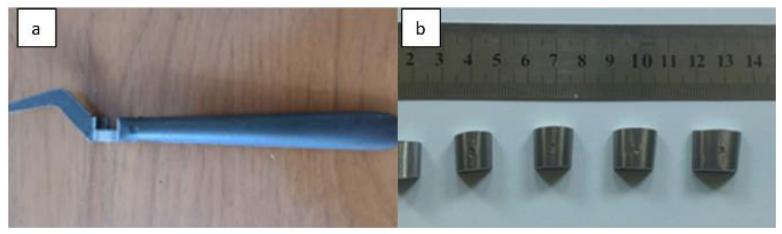

Figure 1. (a) Extraction forceps, (b). Specimen.

Several steps were taken in this experiment, including preparing for the raw material, cutting it into samples, heating them in a furnace room, quenching, and re-entering them into the furnace room for tempering according to the parameters. Hardness testing and microstructure testing were then carried out to evaluate changes in mechanical and physical characteristics.

In general, the heat treatment process's first step was to heat a metal or another alloy at a specific temperature, hold it for a particular period, and then cool it down at a specific cooling rate. Microstructural changes would appear in terms of the phase, shape, or size of the crystal grains in the heating and cooling process. This transformation would alter the properties of the metal or alloy as well.

Heat treatments were carried out on a material with a temperature of $1,050^{\circ} \mathrm{C}$ in a furnace and a holding time of 20 minutes, followed by quenching. The quenching was mainly intended to increase the hardness of steel, and it was typically realised to obtain better wear resistance or strength as suggested by some researchers [3][12][20]. Coupled with a rapid cooling rate, it would result in hard 
martensite. Concerning the study, the quenching process was carried out in a cooling canal with a temperature range of $10-20^{\circ} \mathrm{C}$, as seen in Figure 2.

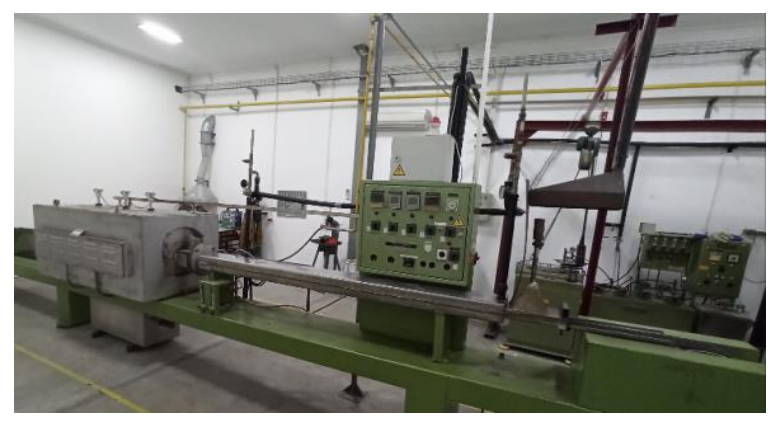

Figure 2. Heating furnace and quenching canal.

After heating and quenching, tempering was performed with temperature variations of 200,400, and $600^{\circ} \mathrm{C}$ with a holding time of 20 minutes. As known in the open literature, the tempering process was oriented to reduces steel's residual stress and increases its toughness and ductility [21]. During the tempering process, the steel would decrease hardness and strength, including an increase in ductility. A decrease would follow the brittleness. The tempering process was carried out in a heating furnace, as shown in Figure 3.

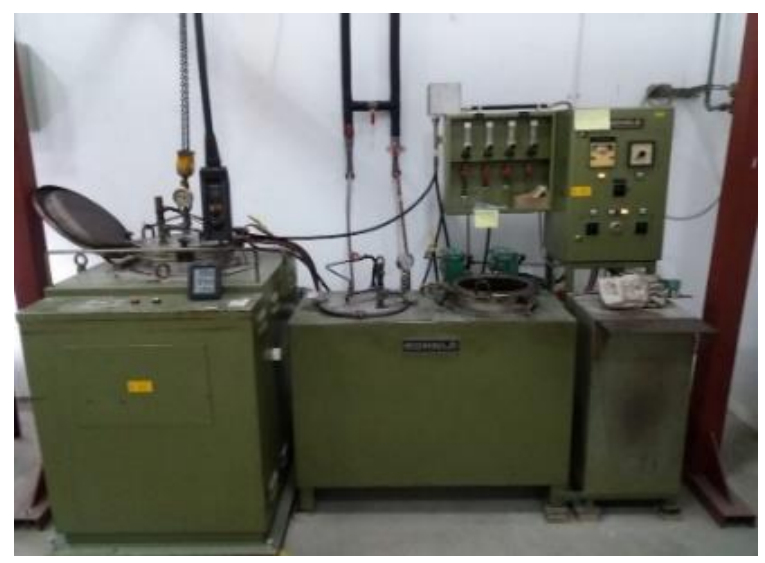

Figure 3. Tempering furnace.

Once the hardening tempering process was completed, a series of hardness and microstructural testing was employed for all specimens referring to the ASTM E384 [22]. The hardness of the materials was tested to examine their mechanical properties. Even though the measurement was carried out only at specific points or areas, the hardness obtained were valid to describe their strength. By this kind of testing, materials would be much easier to be classified as ductile or brittle. Microstructural testing was done to determine the phase arrangement of a test object or specimen. The shapes and sizes of metal crystals, deformation-driven metal damage, and beyond could be identified through the microstructural examination. Before all specimens entered the testing phase, some stages had to be done, such as mounting, grinding, polishing, and etching, as other researchers
[23][24]. All the preparation process are presented in Figure 4.

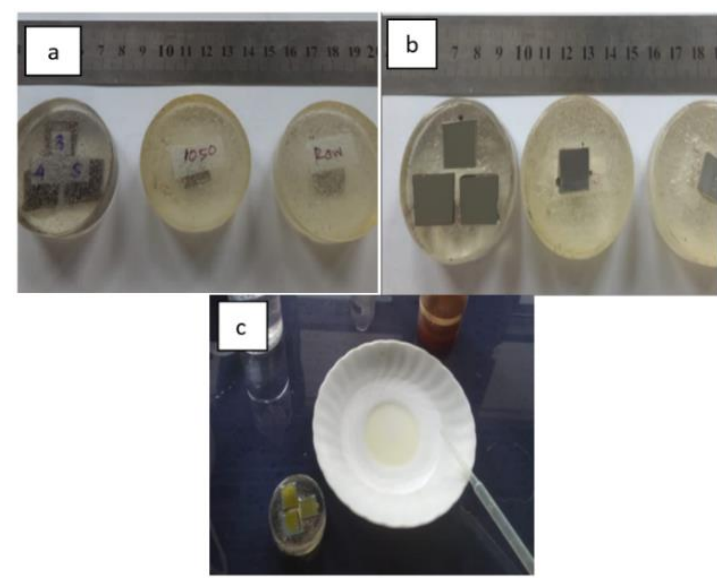

Figure 4. Specimen preparation. (a) Mounting process. (b) Polishing. (c) Etching.

Figure 4(a) is the process of mounting the materials to manage the polishing process. Figure $4(\mathrm{~b})$ is the polishing process after the grinding process with a grit of sandpaper P120, P220, P400, P800, P1000, P1500, $\mathrm{P} 2000$. The results have to be smooth like a mirror, with no scratches. Figure $4(\mathrm{c})$ is the etching process using chemical liquids, namely $\mathrm{HNO}_{3}, \mathrm{HCl}$, and alcohol, as done by Kisasoz et al. [24] .

\section{RESULTS AND DISCUSSION}

\subsection{The characteristics of microstructure using optical microscopy}

Figure 5 gives the microstructure of raw material with $200 \mathrm{X}$ and 400X magnification based on the optical microscopy testing.

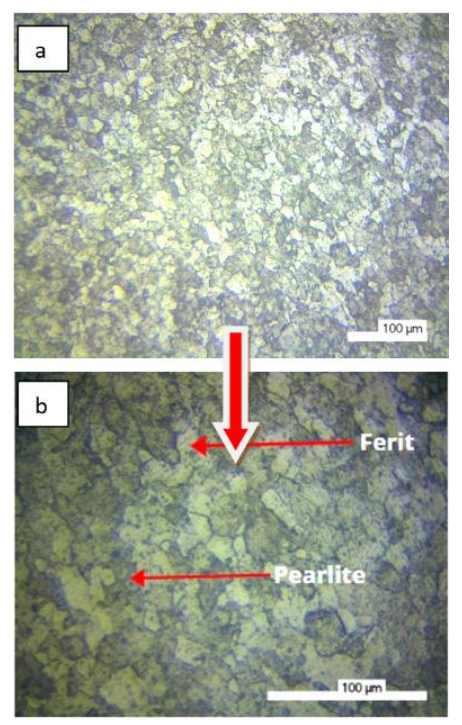

Figure 5. The microstructure of raw material. (a) $200 \mathrm{X}$ magnification. (b) $400 \mathrm{X}$ magnification. 
From the microstructural testing, the raw material contains both ferrite and pearlite structures. The ferrite structure is white in colour, rough in shape, and typically with a maximum carbon content of $0.025 \%$ at $723^{\circ} \mathrm{C}$. Besides, the structure is soft, ductile, and has a body centre cubic (BCC) crystal structure, as found by another researcher [25]. On the other hand, the pearlite structure is grey and large (coarse pearlite). The pearlite structure was formed from two phases, namely the ferrite phase and the cementite phase.

Figure 6 shows the microstructural testing results on stainless steel due to hardening treatment at a temperature of $1,050^{\circ} \mathrm{C}$ and a holding time of 20 minutes. The resulting microstructure consists of soft and dense ferrite structure (light colour), smooth and thick pearlite structure (grey colour), and martensite structure. The blade martensite microstructure is related to a mixture of ferrite and cementite phases, not in lamellar but cementite needles. The martensite phase's existence is due to a rapid cooling rate, preventing the transformation process's atomic particles. This structure has typically hard and brittle properties. It is found that the pearlite and martensite microstructures are more dominant and denser. Consequently, as the austenite temperature in stainlesssteel increases, the austenite grains grew significantly, resulting in coarse martensite grains rather than fine ones. The coarse grains' sizes provide less nucleation for the pearlite transformation, causing the martensite matrix to be more challenging.

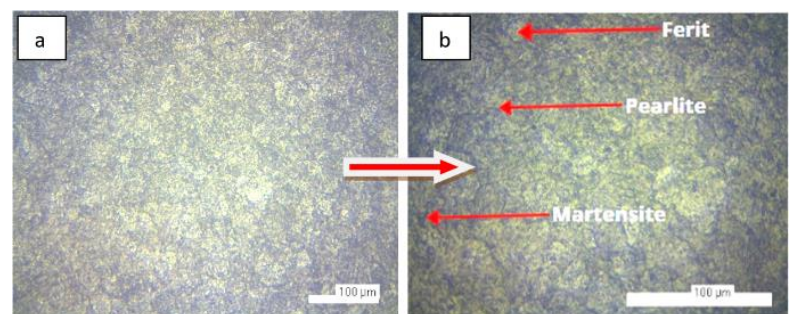

Figure 6. The microstructure of $1,050^{\circ} \mathrm{C}$ hardened material. (a) $200 \mathrm{X}$ magnification. (b) $400 \mathrm{X}$ magnification.

The materials used are hardened at $1,050^{\circ} \mathrm{C}$, held for 20 minutes, and then quenched in a cooling canal. Subsequently, the material is tempered for microstructural testing. The microstructural testing is carried out at varied tempering temperatures of 200,400 , and $600^{\circ} \mathrm{C}$ held for 20 minutes. These temperatures are further classified as low, medium, and high, respectively. The tempering treatment is principally meant to reduce the risk of cracks and internal stress resulting from a rapid cooling rate. The primary purpose is to compare the particle structures' resulting microstructures and shapes after various tempering temperatures. The results of the materials' microstructures with varying temperatures are given in Figure 7.
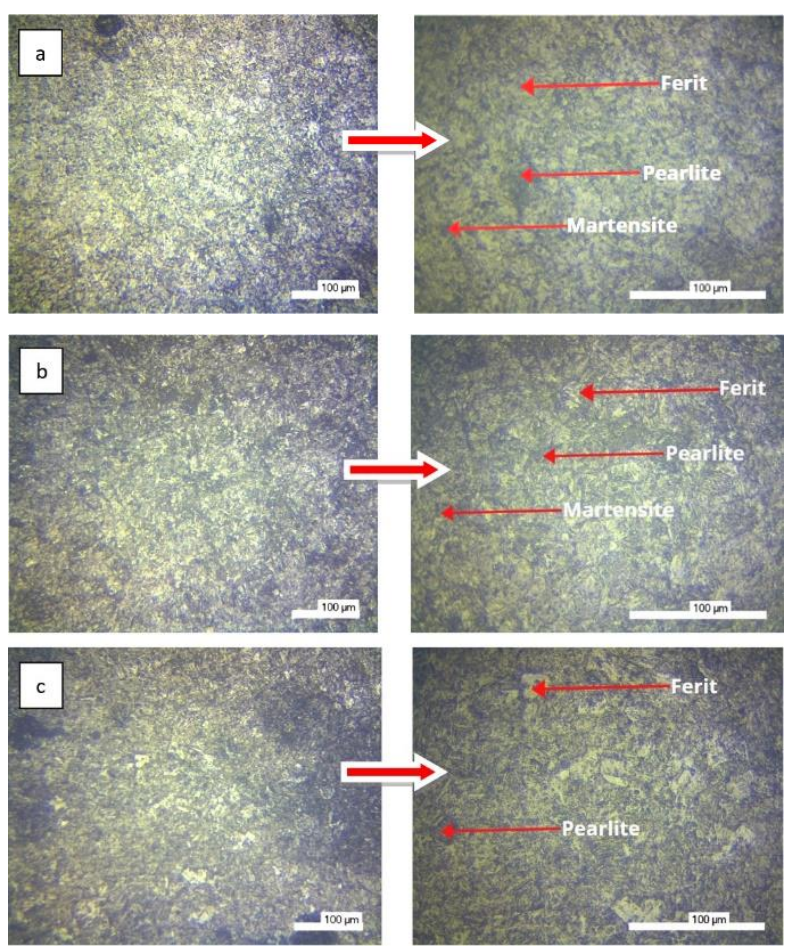

Figure 7. Results of microstructures of tempered materials. (a) The temperature of $200^{\circ} \mathrm{C}$. (b) The temperature of $400^{\circ} \mathrm{C}$. (c) The temperature of $600^{\circ} \mathrm{C}$.

Ferrite, pearlite, and tempered martensite microstructures are formed at a tempering temperature of $200^{\circ} \mathrm{C}$, referring to Isfahany et al. [18]. The microstructure of tempered martensite comes from the decomposed hardened martensite phase. Therefore, it appears to be more ductile but remains challenging. At $200^{\circ} \mathrm{C}$, the microstructure is dominated by tempered martensite structure and pearlite structure, and the atomic arrangement was smoother and tighter. This result is not much different from that of the hardened material. Accordingly, the tempering temperature below $200^{\circ} \mathrm{C}$ has no significant effect on the microstructure and mechanical properties, as found by Sayed and Kheirandish [26].

At a tempering temperature of $400^{\circ} \mathrm{C}$, ferrite, pearlite, and slightly tempered martensite microstructures have been observed. At that temperature, ferrite and pearlite microstructures are quite dominant.

At $600^{\circ} \mathrm{C}$, ferrite and pearlite microstructures are clearly seen. The ferrite and pearlite phases are formed when the austenite phase is altered due to a slow cooling rate. As the tempering temperature increases, the martensite phase shifts into the pearlite and ferrite phases. This transformation eventually changes the physical and mechanical properties. 


\subsection{The characteristics of microstructure using scanning electron microscopy}

Microstructural testing using scanning electron microscopy aims to determine the particles' morphology and size distribution on the specimen materials' surfaces [27-29]. The particle analysis was carried out to obtain the mean areas and diameters of the particles for all tested specimens, namely the raw material, $1,050^{\circ} \mathrm{C}$ hardened specimens, tempered specimens at 200,400 , and $600^{\circ} \mathrm{C}$ with 2000X magnification. The analysis was performed using ImageJ software and the Threshold method, as suggested by Banerjee et al. [30] [31]. The image analysis results using scanning electron microscopy are provided in Figure 8 for the raw material.

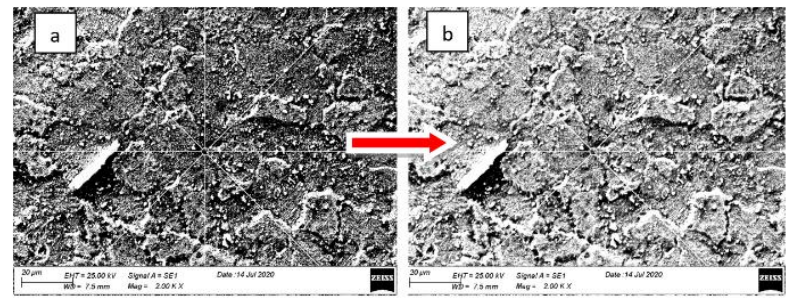

Figure 8. The SEM image processing using ImageJ and Threshold. (a) initial image. (b) Threshold image.

There is a difference between the photos in terms of brightness for the initial SEM image and the Threshold image. The measurement of the raw material using Threshold resulted in a rounded and broad form. This form is similar to that of the microstructural testing using Optical Microscopy as provided in Figure 5.

Figure 9 indicates the results of SEM images of the $1,050^{\circ} \mathrm{C}$ hardened material using ImageJ and Threshold. The threshold method is applied to measure the average area and dimension of the material's particles. The results indicated that the structure's shape is similar to that of the microstructural testing using Optical Microscopy, as shown in Figure 6.

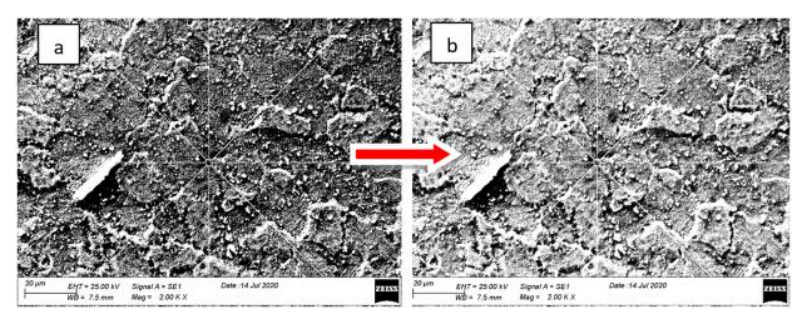

Figure 9. SEM image processing using ImageJ and Threshold.

Table 1 provides the calculation results of the particles' average sizes in the raw material and the heat treatment specimen. The raw material particle is 465.689 $\mu \mathrm{m}^{2}$, while that of the heat treatment specimen is 0.099 $\mu \mathrm{m}^{2}$. It means that the raw material's structure is more extensive than that of the heat treatment specimen's construction, following the fact that the heat treatment specimen has smooth structures. The quenching process at a rapid speed prevents the atoms from transformation and further influenced its hardness. The smaller the dimensions, the higher the hardness, as displayed in Figure 9.

Table 1. Calculation results of average particle sizes

\begin{tabular}{|c|c|c|c|}
\hline No & Specimen & $\begin{array}{c}\text { Area of } \\
\text { Particle }\left(\mu \mathrm{m}^{2}\right)\end{array}$ & $\begin{array}{c}\text { Particle } \\
\text { Diameter }(\mu \mathrm{m})\end{array}$ \\
\hline 1 & Raw Material & 465.689 & 2.596 \\
\hline 2 & $\begin{array}{l}\text { Heat Treatment } \\
1050^{\circ} \mathrm{C}\end{array}$ & 0.099 & 0.330 \\
\hline
\end{tabular}

The tempered specimens have been analysed at 200 , 400 , and $600^{\circ} \mathrm{C}$ with $2000 \mathrm{X}$ magnification using SEM. The results of SEM image processing with ImageJ and Threshold are shown in Figure 10.

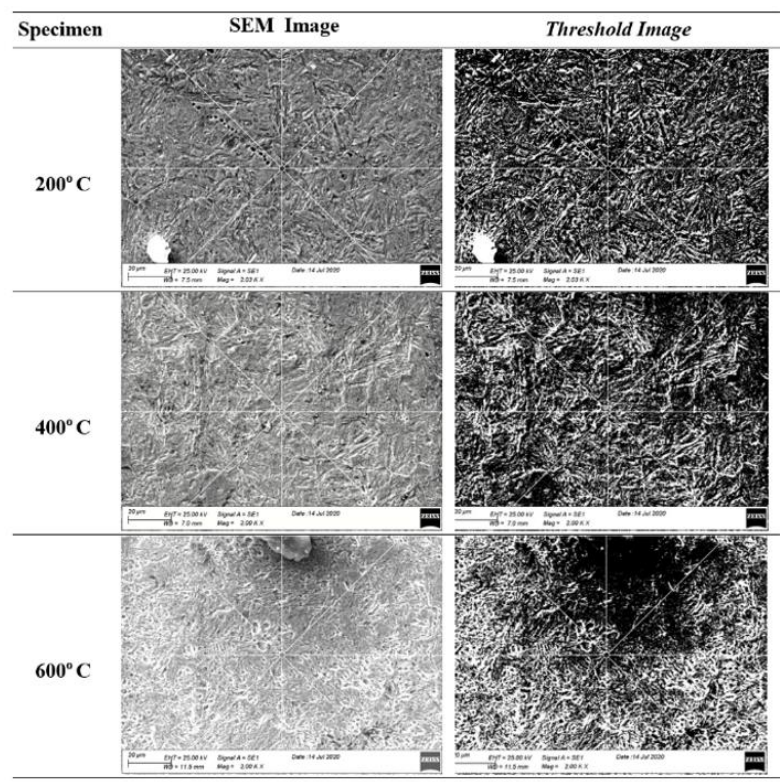

Figure 10. SEM image processing with Image $J$ and Threshold at various tempering temperature.

Table 2. Calculation results of average particle sizes

\begin{tabular}{cccc}
\hline No & $\begin{array}{c}\text { Tempering } \\
\text { temperature }\end{array}$ & $\begin{array}{c}\text { Particle Area } \\
\text { Average }\left(\mu \mathrm{m}^{2}\right)\end{array}$ & $\begin{array}{c}\text { Average Particle } \\
\text { Diameter }(\mu \mathrm{m})\end{array}$ \\
\hline 1 & $200^{\circ} \mathrm{C}$ & 0.149 & 0.392 \\
2 & $400^{\circ} \mathrm{C}$ & 0.255 & 0.492 \\
3 & $600^{\circ} \mathrm{C}$ & 0.527 & 0.587 \\
\hline
\end{tabular}

Based on Table 2 and Figure 10, the specimens' analysis with varying temperatures of 200,400 , and $600^{\circ} \mathrm{C}$ results in the particle areas of $0.149,0.255$, and $0.527 \mu \mathrm{m}^{2}$, respectively. It also produces the average particle diameters of $0.392,0.492$, and $0.587 \mu \mathrm{m}$, respectively. Therefore, it can be inferred that the higher the tempering temperature is, the larger the size of the average particle area and 
diameter will be. A high tempering temperature causes a slow cooling pace, allowing the atomic particles to transform with ease. With such alteration, the hardness of the material decreases.

\subsection{The characteristics of hardness}

In the study, Rockwell Hardness scale $\mathrm{C}$ has been applied to examine the hardness as suggested by ASTM [32]. As seen in Table 3, the hardening and quenching process increases the hardness of Stainless-steel DIN 4021. The hardness of the material changes from 20 to 49 HRC. At a hardening temperature of $1,050^{\circ} \mathrm{C}$, the hardness reached $49 \mathrm{HRC}$ as shown in Figure 5. The ferrite structure was white in colour, rough in shape, and typically with a maximum carbon content of $0.025 \%$ at $723^{\circ} \mathrm{C}$. The structure is soft, ductile, and has a body centre cubic (BCC) crystal structure.

Table 3. Rockwell Hardness.

\begin{tabular}{|c|c|c|c|c|c|}
\hline \multirow{2}{*}{ No. } & \multirow{2}{*}{ Specimen } & \multicolumn{3}{|c|}{ Hardness (HRC) } & \multirow{2}{*}{$\begin{array}{l}\text { Average of } \\
\text { Hardness }\end{array}$} \\
\hline & & 1 & 2 & 3 & \\
\hline 1 & Raw Material & 20 & 19.5 & 20.5 & 20.00 \\
\hline 2 & Hardening $1050^{\circ} \mathrm{C}$ & 49 & 49 & 49 & 49.00 \\
\hline 3 & $\begin{array}{l}\text { Hardening } 1050^{\circ} \mathrm{C} \text {, } \\
\text { Temp } 200^{\circ} \mathrm{C}\end{array}$ & 47 & 48 & 45 & 46.67 \\
\hline 4 & $\begin{array}{l}\text { Hardening } 1050^{\circ} \mathrm{C} \text {, } \\
\text { Temp } 400^{\circ} \mathrm{C}\end{array}$ & 44 & 43 & 44 & 43.67 \\
\hline 5 & $\begin{array}{l}\text { Hardening } 1050^{\circ} \mathrm{C} \\
\text { Temp } 600^{\circ} \mathrm{C}\end{array}$ & 41 & 44 & 42 & 42.33 \\
\hline
\end{tabular}

In the process, the ferrite and pearlite phases are transformed into the martensite phase. In the hardening process above the austenitising temperature, the specimen's carbide also increases, causing the physical and mechanical properties to shift; the martensite phase enlarged, and the hardness increased. In the tempering process at $200^{\circ} \mathrm{C}$, the hardness is 46.67 . There is a slight decrease in the hardness compared to that of the $1,050^{\circ} \mathrm{C}$ hardened material. It occurs due to the low temperature of tempering, allowing the phase transformation to sprint towards the martensite finish up to the tempered martensite phase. The most insufficient average hardness of all tempered materials is $42.33 \mathrm{HRC}$, which is possessed by the test material with a temperature of $600^{\circ} \mathrm{C}$. It is caused by the fact that the austenite phase-shifted into the pearlite phase at this temperature, and the cooling reached the slowest, allowing for coarser and bigger metal grains. However, the hardness remains higher than that of the raw material. The higher the material's tempering temperature, the lower the hardness, as stated by Hariningsih [3]. As illustrated in Figure 10, namely regarding the particle area and particle diameter, where the smaller the values, the higher the material's hardness. The decreased hardness is linked to transforming the martensite phase into pearlite and ferrite phases, resulting from a slow cooling rate [26].

From the average hardness $s$ of the tempered materials examines with varying variables, the permitted hardness for medical devices with the ISO 13485 standard stands at $43 \pm 3$ HRC [2]. The upper limit is $46 \mathrm{HRC}$, and the lower limit is 40 HRC. Therefore, this research's best value is $43.67 \mathrm{HRC}$, obtained at a variable temperature of $400^{\circ} \mathrm{C}$. This figure is close to the acceptable standard of hardness.

\section{CONCLUSION}

An extraction forceps made of DIN 4021 stainless steel has been investigated to evaluate the effects of tempering temperature on microstructure and hardness. The hardness of that medical device materials increases from 20 to $49 \mathrm{HRC}$ by the hardening process. The transformation of the pearlite and ferrite phases into the martensite phase triggers their hardness and ductility. In the tempering process, the permitted hardness for medical devices with the ISO 13485 standard stands at $43 \pm 3$ HRC, with the upper limit being $46 \mathrm{HRC}$, and the lower limit being $43 \mathrm{HRC}$. The microstructure of stainless-steel DIN 4021 is dominated by ferrite and pearlite structures. It adheres that the raw material is composed of a carbon composition of 0.16 to $0.25 \%$. The martensite structure reduces by $30 \%$, which cause a slight decrease of the material hardness. The largest average area and diameter of the tempered specimens examined are $0.527 \mu \mathrm{m}^{2}$ and the diameter of $0.587 \mu \mathrm{m}$ respectively, obtained at a tempering temperature of $600^{\circ} \mathrm{C}$. It means that the higher the tempering temperature, the greater the particle dimension and the lower the hardness.

\section{CONFLICTS OF INTEREST}

The authors declare no conflicts of interest.

\section{ACKNOWLEDGEMENT}

The authors would like to thank the Material Laboratory of the Faculty of Engineering, Universitas Wahid Hasyim Semarang Indonesia, for this research's full support and facilities.

\section{REFERENCES}

[1] G.R. Mirshekari, E. Tavakoli, M. Atapour, and B. Sadeghian, "Microstructure and corrosion behavior of multipass gas tungsten arc welded 3041 stainless steel”, Materials and Design, vol. 55, pp.905-911, 2014. https://doi.org/10.1016/j.matdes.2013.10.064. 
[2] F. Karci, R. Kaçar, and S. Gündüz, "The effect of process parameter on the properties of spot-welded cold deformed AISI 304 grade austenitic stainless steel", Journal of Materials Processing Technology, vol. 209, no. 8, p.4011-4019, 2009. https://doi.org/10.1016/j.jmatprotec.2008.09.030.

[3] H. Hariningsih, S. Sumpena and H. Sukarjo, "The effectivity of used-oil as quenching medium of 42CrMo4 steel for automotive materials", Applied Research and Smart Technology, vol. 1, no. 1, 2020. https://doi.org/10.23917/arstech.v1i1.11.

[4] E. Abbasi, Q. Luo, and D. Owens, "A comparison of microstructure and mechanical properties of lowalloy-medium-carbon steels after quenchhardening", Materials Science and Engineering: $A$, vol. 725, p.65-75, 2018. https://doi.org/10.1016/j.msea.2018.04.012.

[5] A.F. Candelária and C. E. Pinedo, "Influence of the heat treatment on the corrosion resistance of the martensitic stainless steel type AISI 420", Journal of Materials Science Letters, vol. 22, no. 16, pp. 1151$1153,2003$.

https://doi.org/10.1023/A:1025179128333.

[6] J.Y. Park and Y.S. Park, "Effects of austenitising treatment on the corrosion resistance of $14 \mathrm{Cr}-3 \mathrm{Mo}$ martensitic stainless steel", Corrosion, vol. 62, no. 6, pp. 541-547, 2006.

https://doi.org/10.5006/1.3279913

[7] R.E. Smallman and R.J. BiShop, "Biomaterials," Modern Physical Metallurgy and Materials Engineering, science, process, applications, pp. 394405, 1999. http://dx.doi.org/10.1016/B978075064564-5/50013-6.

[8] Ş. Safaltın and S. Gürmen, "Molecular dynamics simulation of size, temperature, heating and cooling rates on structural formation of $\mathrm{Ag}-\mathrm{Cu}-\mathrm{Ni}$ ternary nanoparticles $\left(\mathrm{Ag}_{34}-\mathrm{Cu}_{33}-\mathrm{Ni}_{33}\right)$ ", Computational Materials Science, vol. 183, 109842, 2020. https://doi.org/10.1016/j.commatsci.2020.109842.

[9] ISO 13485: medical devices - quality management systems - requirements for regulatory purposes", Engineering High Quality Medical Software: Regulations, standards, methodologies and tools for certification, 2018.

[10] L.C. Lim, M.O. Lai, J. Ma, D.O. Northwood, and B. Miao, "Tempering of AISI 403 stainless steel", Materials Science and Engineering: A, vol. 171, no. 12, pp.13-19, 1993. https://doi.org/10.1016/09215093(93)90388-U.
[11] T. Senthilkumar and T.K. Ajiboye, "Effect of heat treatment processes on the mechanical properties of medium carbon steel", Journal of Minerals and Materials Characterization and Engineering, vol. 11, no. 2, pp.143-152, 2012. https://doi.org/10.4236/jmmce.2012.112011.

[12] Y. Duan, S. Qu, and X. Li, "Effect of quenchtempering conditions prior to nitriding on microstructure and fretting wear mechanism of gas nitrided X210CrW12 steel", Surface and Coatings Technology, vol. 360, pp.247-258, 2019. https://doi.org/10.1016/j.surfcoat.2018.12.066.

[13] L.D. Barlow and M. Du Toit, "Effect of austenitising heat treatment on the microstructure and hardness of martensitic stainless steel AISI 420", Journal of Materials Engineering and Performance, vol. 21, no. 7, pp. 1327-1336, 2012. https://doi.org/10.1007/s11665-011-0043-9.

[14] X. Lei, Y. Feng, J. Zhang, A. Fu, C. Yin, and D.D. Macdonald, "Impact of reversed austenite on the pitting corrosion behavior of super $13 \mathrm{Cr}$ martensitic stainless steel", Electrochimica Acta, vol. 191, pp. 640-650, 2016.

https://doi.org/2010.1016/j.electacta.2016.01.094.

[15] T. Hryniewicz, K. Rokosz, and M. Filippi, "Biomaterial studies on AISI 316L stainless steel after magneto electro polishing", Materials, vol. 2, no. $1, \quad$ pp.129-145, 2009. https://doi.org/10.3390/ma2010129.

[16] H. Megahed, E. El-Kashif, A.Y. Shash, and M.A. Essam, "Effect of holding time, thickness and heat treatment on microstructure and mechanical properties of compacted graphite cast iron", Journal of Materials Research and Technology, vol. 8, no. 1, pp.1188-1196, 2019.

https://doi.org/10.1016/j.jmrt.2018.07.021.

[17] W. Jiang, J.M. Gong, and S.T. Tu, "Effect of holding time on vacuum brazing for a stainless steel plate-fin structure", Materials and Design, vol.31, no. 4, pp.2157-2162, 2010. https://doi.org/10.1016/j.matdes.2009.11.001

[18] A.N. Isfahany, H. Saghafian, and G. Borhani, "The effect of heat treatment on mechanical properties and corrosion behavior of AISI420 martensitic stainless steel", Journal of Alloys and Compounds, vol. 509, no. 9, pp.3931-3936, 2011. https://doi.org/10.1016/j.jallcom.2010.12.174. 
[19] B. Abbasi-Khazaei and A. Mollaahmadi, "Rapid tempering of martensitic stainless steel AISI420: microstructure, mechanical and corrosion properties", Journal of Materials Engineering and Performance, vol. 26, pp.1626-1633, 2017. https://doi.org/10.1007/s11665-017-2605-y.

[20] P.R. Woodard, S. Chandrasekar, and H.T.Y. Yang, "Analysis of temperature and microstructure in the quenching of steel cylinders", Metallurgical and Materials Transactions B, vol. 30, article:815, 1999. https://doi.org/10.1007/s11663-999-0043-4.

[21] D.R. Barbadikar, G.S. Deshmukh, L. Maddi, K. Laha, P. Parameswaran, A.R. Ballal, D.R. Peshwe., R.K. Paretkar, M. Nandagopal and M.D. Mathew, "Effect of normalising and tempering temperatures on microstructure and mechanical properties of $\mathrm{P} 92$ steel", International Journal of Pressure Vessels and Piping, vol. 132-133, pp.97-105, 2015. https://doi.org/10.1016/j.ijpvp.2015.07.001.

[22] P. Garg, A. Jamwal, D. Kumar, K.S. Sadasivuni, C.M. Hussain, and P. Gupta, "Advance research progresses in aluminium matrix composites: manufacturing \& applications", Journal of Material Research and Technology, vol. 8, no. 5, pp. 49244939, 2019.

https://doi.org/10.1016/j.jmrt.2019.06.028.

[23] A. Oddy and D.A. Scott, "Metallography and microstructure of ancient and historic metals," Studies in Conservation, The Getty Conservation Institute, Tien Wah Press, Singapore, 1992.

[24] A. Kisasoz, A. Karaaslan, and Y. Bayrak, "Effect of etching methods in metallographic studies of duplex stainless steel 2205", Metal Science and Heat Treatment, vol. 58, pp.704-706, 2017. https://doi.org/10.1007/s11041-017-0081-5.

[25] S. Fang, W. Chen, and Z. Fu, "Microstructure and mechanical properties of twinned $\mathrm{Al} 0.5 \mathrm{CrFeNiCo}$ $0.3 \mathrm{C} 0.2$ high entropy alloy processed by mechanical alloying and spark plasma sintering", Materials \& Design, vol. 54, pp.973-979, 2014. https://doi.org/10.1016/j.matdes.2013.08.099.
[26] A.A. Sayed and S. Kheirandish, "Affect of the tempering temperature on the microstructure and mechanical properties of dual phase steels", Materials Science and Engineering: A, vol 532, pp.21-25, 2012. https://doi.org/10.1016/j.msea.2011.10.056.

[27] R. Heard, C.R. Siviour, and K.I. Dragnevski, "In situ SEM analysis of surface oxidation mechanisms in carbon steel during vacuum heat treatment", Materialstoday: Proceedings, vol. 33, part 4, pp.18981903, 2020.

https://doi.org/10.1016/j.matpr.2020.05.396.

[28] S. Maaß, J. Rojahn, R. Hänsch, and M. Kraume, "Automated drop detection using image analysis for online particle size monitoring in multiphase systems", Computers Chemical Engineering, vol. 45, pp.27-37, 2012.

https://doi.org/10.1016/j.compchemeng.2012.05.0 $\underline{14}$.

[29] S.J. Blott and K. Pye, "Particle size distribution analysis of sand-sized particles by laser diffraction: An experimental investigation of instrument sensitivity and the effects of particle shape", Sedimentology, vol. 53, no. 3, pp.671-685, 2006. https://doi.org/10.1111/j.1365-3091.2006.00786.x

[30] S. Banerjee, P.C. Chakraborti, and S.K. Saha, "An automated methodology for grain segmentation and grain size measurement from optical micrographs", Measurement, vol. 140, pp. 142-150, 2019. https://doi.org/10.1016/j.measurement.2019.03.04 $\underline{6}$

[31] F. Papadopulos, M. Spinelli, S. Valente, L. Oroni, C. Orrico, F. Alviano, and G. Pasquinelli, "Common tasks in microscopic and ultrastructural image analysis using ImageJ", Ultrastructural Pathology, vol. 31, no. 6, pp.401-407, 2007. https://doi.org/10.1080/01913120701719189.

[32] ASTM E18/18M-11, "Standard test methods for rockwell hardness of metallic materials", ASTM International, 2018. 